\title{
EL LIDERAZGO HUMANISTA ÉTICO EN LAS ORGANIZACIONES
}

\section{THE HUMANIST ETHICAL LEADERSHIP \\ IN THE ORGANIZATIONS}

\author{
Mario Jesús Aguilar Camacho y Edwin Hernando Alonso Niño² \\ Universidad de Guanajuato, Guanajuato, México ${ }^{1}$ \\ Universidad Santo Tomás, Tunja, Colombia²
}

\section{Resumen:}

Este trabajo de investigación se replantea el papel protagónico que le corresponde asumir a los líderes y sus seguidores para lograr un desempeño exitoso de las organizaciones actuales. La idea se genera una vez que han sido sometidos a fuerte valoración crítica y a ser considerados como agotados y rebasados algunos de los enfoques y modelos de liderazgo cimentados en teorías idealistas, empiristas, vitalistas, materialistas, conductistas, individualistas. Las conclusiones de arribo evidencian la necesidad de gestionar en las organizaciones un liderazgo transformador y humanista, sustentado en una filosofía realista, orientada sobre principios éticos, valores y competencias; en pocas palabras, un retorno al modelo de liderazgo "político" similar al de los griegos: al servicio de la comunidad, la polis.

Palabras clave: Ética humanista, filosofía organizacional, nuevo liderazgo.

\section{Summary:}

This work of investigation rethinks the leading paper that corresponds to him to assume the leaders and his followers to achieve a successful performance of the current organizations. The idea is generated as soon as they have been submitted to strong critical valuation and for being considered like exhausted and exceeded some of the approaches and models of leadership established in idealistic theories, empirists, vitalists, materialistics, behaviorists, 
individualistics. The conclusions gotten, demonstrate the need to manage organizations with a transforming and humanist leadership, sustained in a realistic philosophy, orientated by the ethical beginning, values and competitions; in simple terms, a return to the model of "political" leadership similar to the one of the Greeks: to the service of the community, the polis.

Keywords: Humanist Ethics, organizational philosophy, new leadership.

\section{Introducción}

El mundo ha cambiado profundamente, sus efectos se aprecian cada momento y en todas partes. Se evidencian cuestiones impensables hasta avanzados tres cuartos del siglo XX: la contribución de las nuevas tecnologías en todos los campos del saber, lo imprescindible de internet, el auge de los medios de comunicación, lo irreversible de las redes sociales, la valiosa herramienta de las grandes bases de datos, el advenimiento de mercados emergentes, una amplia profesionalización del empleo, la coparticipación virtual, la responsabilidad social empresarial en temas ecológicos y de sustentabilidad, etc. Ante este escenario flota en el aire la interrogante ¿ ¿Son válidas y efectivas las prácticas corporativas y de gobierno de las organizaciones en el mundo actual? La necesidad nos indica que para ser competitivos se requiere innovar, y esto urge a desechar viejos modelos gerenciales y demoler muchos de los arcaicos principios de la tradicional ciencia de la dirección de empresas y de la toma de decisiones, el liderazgo.

Se atribuye a Nicolás Maquiavelo la frase "El fin justifica los medios", fundamento de la razón de Estado, la cual representa la pretendida justificación que emplean algunos gobernantes o dirigentes -que en transferencia de ideas al contexto actual se puede decir que son los actuales líderes, ya sea en instituciones públicas, bien en empresas u organizaciones privadas- que en sus decisiones han de estar por encima de la ética, la moral o el derecho, para llevar a cabo sus planes y conseguir sus objetivos.

Esta proposición ha sido patrocinada por los defensores de la denominada doctrina de la conducta utilitarista y eficientista del Bien Superior, soportada sobre la idea de que el todo es mayor que la parte, por lo cual, en las organizaciones el dirigente debe a toda costa alcanzar las metas corporativas, sin escatimar medios éticos, morales o apegados a derecho. Dicha cosmovisión se enfrenta a la concepción Humanista, de corte aristotélico tomista, que se construye sobre el argumento lógico de que el árbol bueno da frutos buenos y el árbol malo da frutos malos, por lo tanto el "fin no justifica los medios"; y el fin es el bien común en la organización.

Es evidente que la globalización ha transmutado los antiguos órdenes económicos, 
sociales, políticos y culturales; por lo cual resulta imprescindible hacer ajustes a las instituciones y organizaciones; y a esta situación no escapa la tarea directiva empresarial. Destaca el hecho de que el sistema empresarial fue trazado para enfrentar y resolver problemáticas particulares en su tiempo, y que no necesariamente se adaptan a la realidad de hoy; ahora se requieren respuestas efectivas, actualizando las actitudes, procesos, actividades y estructuras de las organizaciones a las nuevas condiciones de mercado, surgidas en los escenarios regionales e internacionales, en los que la competencia es tan feroz y mutante, que resulta muchas veces confuso tomar decisiones que sean de algún modo provechosas o ventajosas para las corporaciones. En esta dirección, el mundo globalizado parece haber perdido sus valores, y la generalidad se ha dejado dominar por el consumismo, el hedonismo y el individualismo egoísta. En el mundo de los negocios, despuntan casos como el de Enron, WorldCom o Parmalat, por citar muestras del precipicio antiético en el actual ámbito empresarial.

Retomando tema, en las organizaciones, sobre todo en las empresariales, la clave para sobrevivir es adaptarse con sus debilidades y competencias -capacidades, habilidades y recursos- al entorno, que presenta oportunidades y amenazas. Sobreviven las empresas -como en la selección natural de Darwin-, no las especies más fuertes, sino aquellas que se adaptan mejor; y para eso se requiere de una acertada toma de decisiones (Ruíz, 2013).

En esa dirección apunta Ruiz, (2013), pues si acudimos a la lista de las 25 empresas más grandes de Estados Unidos, que publica la revista Fortune desde 1955. ¿Cuántas empresas de las 25 más grandes en 1955, permanecen en 2012? La respuesta es sólo cinco, y una es General Electric, que ocupa la posición ocho, demostrando que esta organización ha sabido adaptarse al entorno. Otras dos empresas que no estaban en 1955, pero ahora sí figuran Walmart, fundada en 1962, con el lugar número 2, y Apple, fundada en 1976, en la posición 7. Por ello, ambas son ejemplo de una buena adaptación al mercado. En ese sentido, nosotros pensamos que el denominador común y la clave de una buena estrategia de negocios es: la toma de decisiones, el liderazgo para la adaptación.

Hay una notable diferencia entre el líder y el iluso: el soñador iluso es una persona capaz de plantearse grandes ideas, pero incapaz de hacerlas reales, de concretizarlas, de plasmarlas en la realidad. En cambio el líder es magnánimo, conjuga grandes sueños con grandes realizaciones, tiene la mirada puesta lejos y al mismo tiempo en el objetivo concreto. Es bien sabido que un auténtico dirigente o guía inspira confianza porque hace las cosas bien, consuma sus cometidos, honra su palabra comprometida, cumple sus promesas, orienta el rumbo y sostiene los ánimos de los integrantes de la organización, sobre todo en los tiempos nebulosos. Esa forma de ser del líder se le conoce como profesionalismo, que consiste en saber y hacer bien las cosas, ser pertinente, creativo; capaz de avizorar el futuro, elegir y aplicar los medios para conseguir las metas y fines de la organización. También está el dirigente que no tiene miramientos en conseguir lo que desea empleando medios de cualquier naturaleza. 
Así, en el mundo de los negocios, en estos tiempos nadie puede negar el papel protagónico que desempeñan los líderes como guías de las organizaciones para obtener productividad y competitividad, las cuales deriven consecuentemente en la permanencia y el éxito de la empresa. El dilema está en qué tipo de líder ser o en identificar a quién se debe seguir; pero, principalmente se afronta la disyuntiva: ¿conseguir el éxito económico de la empresa, a como dé lugar, o bien, lograr las metas en conjunto para el bien común de la organización y sus stakeholders? El liderazgo actual corre entre dos polos de conducta: amoral o ética.

Este artículo pretende realizar una delineación de los conceptos liderazgo y ética -sin pretender, en tan poco espacio, agotar el tema-, resaltando la importancia de ambos términos en el mundo de las organizaciones, enfocado principalmente al ámbito empresarial; se estudia la relación existente entre ambos conceptos, es decir, el liderazgo ético como tal. Se enfoca a contrastar dos modelos de liderazgo y su efectividad en las organizaciones de la actualidad: el de corte maquiaveliano, en el que prevalece la divisa de alcanzar el éxito a toda costa, y el humanista del bien común. Para ello se argumentará, entre otras cuestiones, la forma en que debería ejercerse el liderazgo ético, las características y virtudes preponderantes que caracterizan a un líder de este perfil, así como las amenazas a las que éste se enfrenta en su reto de fomentar un liderazgo centrado en las personas, acorde a las exigencias del siglo XXI.

\section{El liderazgo}

La toma de decisiones es una tarea básica del directivo de la organización. Al sistematizar la forma en que se toman las decisiones en el contexto adecuado, se puede asegurar que cada decisión sea la mejor posible. Sobre el tema del liderazgo es abundante la literatura existente; todo ello, en función de que son los lideres quienes conducen, cohesionan y activan a la fuerza de trabajo al logro de propósitos compartidos en las organizaciones; por lo mismo, también se constituyen en factores determinantes e impulsores de los procesos de cambio en los ámbitos económicos, políticos y sociales que históricamente se han generado en la historia de la humanidad.

Leonard White (1964) manifiesta

El arte de la administración ha sido una de las posesiones esenciales del hombre. La construcción de las pirámides fue una proeza administrativa de primer orden tanto como una realización técnica notable. La administración de los negocios del Imperio Romano, con los medios de que entonces se disponía, fue una gigantesca tarea bien ejecutada durante siglos. Organizar el Estado nacional sobre el feudalismo de la Edad Media y crear ejércitos disciplinados, de muchedumbres indisciplinadas, de caballeros cubiertos con armaduras, fueron hazañas administrativas tanto como políticas, a pesar de las grandes diferencias, en cultura y tecnología. El proceso de la administración, a través de los siglos, fue intrínsecamente el mismo que ahora hace posibles grandes empresas de negocios, sistemas continentales de gobierno y los comienzos de un orden universal. (p. 38)

Simon, Smithburg y Thompson (1956), iniciaron su obra clásica Administración Pública, con el siguiente párrafo: 
Cuando dos hombres se ayudan mutuamente a mover una piedra que ninguno de los dos puede mover por sí solo, han aparecido los rudimentos de la administración. Este acto tan simple tiene dos características esenciales de la compleja maraña que se llama administración. Existe un propósito: mover la piedra, y hay una acción conjunta: varias personas combinan su fuerza para hacer algo que ninguna de ellas podría hacer por sí sola. En su sentido más amplio, "Administración" puede definirse como las actividades de grupos que cooperan para alcanzar determinados objetivos. (p. 89)

Del análisis del parágrafo anterior se infiere que el ejercicio del liderazgo se remonta prácticamente a los orígenes de la humanidad, desde que el hombre comienza a convivir en grupos, y se hizo necesaria la presencia de un guía o líder para organizar las diferentes actividades en la búsqueda de la satisfacción de necesidades colectivas. Existen documentos que evidencian que los sumerios, cinco mil años antes de Cristo, practicaban el liderazgo organizacional; de igual manera ocurre en las civilizaciones: Griega, Egipcia, China, así como en Macedonia, Babilonia y posteriormente en la Edad Media (Murati \& Pozo, 2013).

Reforzando el postulado anterior, Duguit (1926) -ver también a Ríos (1975) - dijo que: "No hay ninguna distinción entre el poder ejercido por un jefe de horda y el jefe de gobierno moderno. Es una cuestión de grado, pero no de naturaleza. Se parte del postulado de que en todo agregado humano, de carácter estable y organizado, llámese en la antigüedad familia, tribu, gens, municipio, existía el poder -ya sea del pater familiae, del jefe o de quien encabezaba la organización-" (p. 20).
En esta orientación, los dirigentes o líderes de las actuales organizaciones, que representan a una comunidad que tiende a satisfacer finalidades muy amplias y variadas, tienen que estar dotados forzosamente del poder de dirección, de mando. Georges Burdeau (1981) sostiene que el carácter político es inherente a todo acto, hecho o situación que ponga de manifiesto la existencia, en un grupo humano, de relaciones de autoridad y de obediencia establecidas con el propósito de alcanzar un fin común. Ríos (1975), afirma que lo político se concibe como una realidad circular, en cuyo centro geométrico -centro de interés- se encuentra el Poder o facultad de mando; una situación, por tanto, de jerarquía.

Es reconocido que fue a partir de la revolución Industrial, iniciada durante el siglo XVIII en Inglaterra, cuando la práctica y estudio del liderazgo comienza a tomar mayor relevancia en las organizaciones -con la sustitución de los talleres y la aparición de las fábricas-, hasta convertirse en un tema de estudio tanto en centros de investigación especializados, como en universidades, organizaciones, por su posición determinante en el cometido de las empresas contemporáneas.

Los estudios sobre la administración pública se inician en el siglo XIX, a pesar de que la administración es la parte más visible del Gobierno y es tan vieja como el gobierno mismo. Con anterioridad los teólogos, filósofos y juristas se habían preocupado por otros aspectos estatales, muy interesantes desde luego como la Constitución, la soberanía, el poder público, las prerrogativas regias, los sistemas de gobierno, las relaciones entre el monarca y el pueblo; los privilegios 
de que gozaban unos cuantos frente a la aguda pobreza de las masas populares; el antagonismo entre el poder espiritual y el secular, etc. Pero no paraban mientes en la administración, esto es, en la organización, métodos y sistemas que empleaban los gobernantes en su cometido -si es que los había- ni examinaban si la administración era o no eficiente. (Wilson, 1887 , citado por Ríos, 1975, p. 364)

Henri Fayol, contemporáneo de Federico Winslow Taylor, publicó su obra más conocida Administración Industrial y General en el año 1916, y El despertar del Espíritu Público, posteriormente; en las cuales explica que en las empresas industriales se encuentran características que son comunes a cualesquiera otras, de donde se desprenden diversos principios de organización y que a su juicio, es preciso trasladarlos al ámbito de la empresa por antonomasia: el Estado. El fundador del Centro de Estudios Administrativos de París, destacó que:

Hasta ahora el empirismo ha reinado en la administración de los negocios. Cada jefe gobierna a su manera sin inquietarse por saber si hay leyes que rigen la materia. La ausencia de doctrinas deja libre curso a todas las fantasías, hay que introducir el método experimental: decir, observar, recoger, clasificar e interpretar los hechos. Sacar reglas. (Fayol, citado en Ríos, 1975, pág. 369)

\section{El liderazgo de maquiavelo}

En sus obras, Nicolás Maquiavelo se preocupó de ofrecer un perfil de lo que él consideraba como el ideal del estadista. Expuso sus conclusiones sobre los modos esenciales de obtener, conservar e incluso perder el poder: por la llamada virtú (energía, empuje, resolución, talento, valor indómito y feroz, y por las propias armas), o por la fortuna (y las armas de otro); o por perfidia, o gracias al favor prestado por sus conciudadanos. También llega a concebir a la fortuna (azar), como la coyuntura individual o social que lleva al monarca a consolidar el poder. Pero, primordialmente en El Príncipe, personifica el poder soberano en el gobernante, cuyas cualidades deben ser expresión de la virtú (expresión que trastocó el concepto de la virtud) (Maquiavelo, 1983). En la anterior concepción, la virtú es una técnica; una conducta tecnificada y calculadora para adquirir, conservar y expandir el poder político. Asegura el florentino que si el príncipe, en un principado nuevo o adquirido, sigue las reglas del cálculo político, logrará mantener el poder. Para Maquiavelo el poder político, al cual considera como una técnica, está "más allá del bien y del mal", es amoral (que no inmoral de necesidad, sino contingente, según las necesidades del líder) (Del Aguila, 1999).

Sobre esta temática, Passerin D’Entréves (1970) comenta:

No existe en Maquiavelo ni, consecuentemente, en el "maquiavelismo" más reglas para el ejercicio del poder soberano que el poder soberano mismo. Es decir, el poder tiene su propia lógica como si se tratara de un mecanismo con sus resortes internos de funcionamiento. Maquiavelo pone el de conveniencia. Resultando así que el poder político no busca la justicia social, ni la verdad sobre el hombre, sino tan sólo la utilidad para adquirir y conservar el poder. El poder político, de 
acuerdo al método de Maquiavelo, no busca modelos ideales sino aquello que hoy en día se denomina real politik, es decir, el nudo hecho político que se presenta como "dato" (lo dado). Baste con leer el famoso Capítulo XV de su opúsculo. (p. 245)

Dice Jordi López (2009), que Maquiavelo no tenía ninguna duda sobre qué era liderar. Para él, desde la perspectiva del siglo XVI, ser un buen líder significaba tener astucia, ser pragmático, poseer inteligencia, tener encanto personal y ser despiadado. Si en el texto de su obra El Príncipe, la palabra príncipe es sustituida por líder, con esto se tiene un buen libro sobre liderazgo (según Maquiavelo). En sus reflexiones, el florentino se acerca al tema del liderazgo en la esfera política y posteriormente la reflexión fue trasladada al campo de las organizaciones. Maquiavelo abre una primera teoría sobre el liderazgo cuya vigencia abarca el período del siglo XVI hasta 1940 aproximadamente, en un primer momento, aunque vuelva a tener cierto realce en los últimos años. El pensamiento de Maquiavelo era profundamente pesimista, consideraba al ser humano malo por naturaleza; es decir, él pensaba que las personas sólo se movían por intereses individuales, y por ello los líderes sólo buscaban su propio beneficio. Maquiavelo propone metafóricamente un líder camaleónico, adaptativo "cambiar según soplen los vientos". El pensamiento de Maquiavelo sienta las primeras bases de la teoría del liderazgo basado en las capacidades o características personales inherentes a los líderes.

\section{El humanismo de los griegos}

"Quien no conoce su pasado está condenado a repetirlo", esta frase cuya autoría se atribuye a diferentes personajes -Homero, Marco Tulio, Cicerón, Napoleón-, ha llegado a convertirse en un adagio popular, el cual aparece escrito en el antiguo campo de concentración de Auschwitz, Polonia, pues en este lugar se rememora uno de los episodios más dolorosos y conocidos de la historia de la humanidad que no deben repetirse, el holocausto judío.

En un sentido positivo, el pasado sí debe repetirse; así se evoca y añora a los griegos clásicos, quienes abogaban por una educación liberal dirigida a la enseñanza de crear al ciudadano modelo y al hombre libre. De una u otra forma, el mundo occidental refiere la continuación y síntesis de las civilizaciones de Grecia y Roma clásicas. Esta última, conquistadora por la fuerza de la primera; la primera dominante de la segunda por el espíritu y la cultura. Se aseguraba que un griego no es griego por raza, sino por espíritu, por el conocimiento que tiene de su cultura (Marrou, 200o). Por antonomasia, es innegable la huella perenne del realismo humanista de Aristóteles sobre filósofos moralistas como Kant, Scheler, Hartmann. En el tema del liderazgo, el estagirita se deja sentir sobre el enfoque ético de Lussier y Achua (2003); es visible su influencia sobre la percepción y postura del liderazgo de Álvarez y colaboradores (2002). Tampoco se puede soslayar la marcada influencia del pensamiento aristotélico sobre la concepción del liderazgo ético postulada por Etkin (2005), al igual que su incidencia en la teorética del líder diseñada por Soto y Cárdenas (2007), así como en algunos otros con posturas éticas materialistas e idealistas como la de Mendoza y Mendoza (20o8). Es decir que varios autores contemporáneos, siguen 
la visión aristotélica, impregnada de un humanismo muy particular.

\section{Liderazgo humanista en las organizaciones}

Diversas doctrinas económicas y de negocios sostienen que la empresa es una realidad puramente utilitaria y sustentan que su única finalidad consiste en obtener beneficios económicos para los empresarios. Dar como hecho consumado que la empresa es solamente utilitaria supone que las personas que prestan sus servicios en ella no son más que instrumentos y herramientas. Sostener que el único objetivo de la empresa es obtener rendimientos económicos, semejaría a aseverar la validez universal del postulado de Hobbes de que "el hombre es el lobo del hombre".

En el mundo actual, en el que la sociedad ha perdido en gran medida sus valores, dichas teorías parecen no ser suficientes, siendo esencial que el concepto de liderazgo sea replanteado por líderes y organizaciones, incorporando la dimensión ética en su actuar.

El liderazgo ético presenta innovadoras alternativas, que se alejan de la máxima maquiavélica de que "el fin justifica los medios", y propone al empresario y al directivo incursionar en esta fórmula de liderazgo con la cual se pretende el respeto a la dignidad del personal, y su consideración para innovar en la mejora de procesos y tareas que beneficien a la empresa y permitan establecer buenas prácticas de gobierno corporativo, con las cuales, a su vez, se fomente un óptimo clima laboral en el que permeen los axiomas incluyentes y participativos de ganar, ganar, así como el de "la unión hace la fuerza".

Para quien niegue que la empresa contenga filosofía, baste leer cualquier manual para la elaboración de un Plan de Negocios. La apertura comercial, el desarrollo tecnológico, la alta competitividad entre los productos y servicios, ha mostrado la necesidad imperativa de contar con tres herramientas clave para el éxito de las organizaciones que son "Filosofía", "Visión" y "Misión" de la empresa, para poder establecer sus objetivos y metas.

$\mathrm{Al}$ respecto, refiere Oppenheimer (1998):

Una encuesta realizada en 17 países de América Latina, llegó a la conclusión de que el primer rasgo característico que sobresale de la cultura latinoamericana lo conforman los bajos niveles de confianza interpersonal. La encuesta reveló que un $78 \%$ de los latinoamericanos desconfían del prójimo en una proporción mayor que en Estados Unidos y Europa, y con altos costos, pues lo inversionistas intentan canalizar sus inversiones $\mathrm{y}$, cuando lo hacen, toman precauciones legales extraordinarias. Como las empresas deben gastar en publicidad, estos costos se pasan a los consumidores no solo en términos de precios sino en ambientes culturales denominados por las exigencias de la mercadotecnia. Un bombardeo de spots publicitarios, muchas veces de pocos segundos de duración, pero con mayor frecuencia. (p. 145)

Francis Fukuyama (1995) indicó que en la actualidad ya no es posible divorciar la vida cultural de la económica. En una era en la que el capital social puede resultar tan 
importante como el capital físico, solo aquellas sociedades con alto grado de confianza social podrán ser capaces de crear las organizaciones flexibles y multinacionales que están siendo necesarias para competir en el mundo moderno. Como señalan Kouzes y Posner (2005), cualquier persona por el hecho de serlo tiene la potencialidad de convertirse en líder, pues el liderazgo es un conjunto de prácticas observables que se pueden aprender. En el liderazgo humanista, el líder es pedagogo, educa a los demás, sobre todo con el ejemplo constante y diario. Él tiene el destino y el rumbo claros; siente pasión por su trabajo y está entregado a su trabajo, por lo mismo irradia y contagia su seguridad en lo que hace. Bennis y Nanus (2001), indican que otra cualidad es su capacidad para entusiasmar a la gente. El liderazgo humanista, además, procura dar sentido al trabajo de las personas en la empresa, y esto viene asociado con el cambio. De este modo, liderazgo e innovación son realidades que integran un binomio inseparable.

Finalmente, el líder humanista es humilde y se sabe prescindible, por ello prepara a fondo a aquella persona o personas que puedan relevarle. Su sentido de la responsabilidad le lleva a actuar de este modo. Se refiere a que existen siete claves que identifican el ejercicio de un liderazgo humanista "siete ces", que son: coherencia, convicción, credibilidad, confianza, comunicación, compromiso y conciencia.

\section{Liderazgo y empresa}

Dice el viejo adagio "renovarse o morir", y este no es solo un pronunciamiento más, es una actitud que deben poner en práctica no sólo las personas, sino todas las organizaciones. Por lo mismo, dicha referencia es válida en el mundo empresarial, ahora más que nunca, cuando la globalización ha tomado auge y observa cambios vertiginosos que obligan a buscar nuevas formas y alternativas de desarrollo para competir, y no solo sobrevivir en los mercados.

En ese orden de ideas, para las empresas -sin importar su tamaño, los recursos que posea, su mercado, industria o nivel de tecnificación- resulta indispensable la comprensión del "nuevo orden mundial". No basta con sólo mejorar las viejas formas de operación y administración, es importante incorporar elementos de futuro que permitan un desarrollo sustentable, y un crecimiento de acuerdo a la nueva dinámica social: "innovar es la clave" (Jossey-Bass, 1998).

En el nuevo entorno de la mundialización, los clientes, los consumidores y las empresas buscan servicio, calidad y menor precio, y si en sus redes comerciales de distribución no encuentran lo anterior, entonces prescindirán de ellas. Al respecto, sobresale el papel que desempeña uno de los pilares de la organización: la "persona”, el elemento o capital humano. Este factor es considerado como el principal agente para incrementar la capacidad competitiva. Se trata de aportar ideas para que las organizaciones aprovechen las ventajas competitivas que ofrece este escenario mundial de los negocios.

En la Ciencia de la Administración, específicamente el área de Dirección, se atribuye a Chester Barnard (1968) ser el pionero en teorizar la relevancia de la ética para el liderazgo, en su obra The Functions of 
the Executive, cuya primera edición es de 1938, donde sostiene que:

El liderazgo está compuesto por dos dimensiones: una técnica y otra ética, o de responsabilidad. Las organizaciones perduran en proporción a la altura de la moralidad según la cual son gobernadas (...). Por lo que la fortaleza de una organización depende de la calidad de su liderazgo; y esa calidad, a su vez, deriva de la categoría de la moralidad sobre la que se apoya. (p. 231)

Indican Mendoza y Mendoza (2008), que la gerencia de las personas y de las tareas incluye: coordinación, toma de decisiones, liderazgo, influencia, planificación y organización, así como el manejo de conflictos. La situación actual de la economía y el desarrollo del mercado global, hacen imperiosa la actualización permanente y crecimiento de una fuerza laboral altamente calificada y motivada. Para el logro de esto, las organizaciones están descubriendo que las competencias de supervisores y gerentes deben cambiar hacia una práctica ética. A este respecto debe notarse que aunque en el campo de las actividades humanas y en organizaciones quizá el valor ético sea el más relevante como una observación integral atendiendo a la dignidad de la persona que nunca puede ser rebajada al rango de mero recurso o de inversión en capital. En la praxis es lógico que las decisiones humanas en tales contextos atiendan también a otros tipos de valor, que podrían más bien verse como condicionantes externas respecto a la consecución de los objetivos de valor humano.

Entre las características y los rasgos del liderazgo humanista se puede identificar una respuesta ética porque las acciones y el comportamiento correcto (integridad) son la parte medular de las funciones desempeñadas, y el éxito de la organización se funda en los valores morales y en la responsabilidad social de sus líderes. Dice Welch (citado por McFarland, Senn \& Childress, 1997), que es necesario vivir según nuestros valores, para potenciar todas las mentes y comprometerlas para triunfar en este entorno globalmente competitivo. Además, el autor anteriormente mencionado indica que las organizaciones no pueden competir con empowerment de alto desempeño sin desarrollar a través de un liderazgo ético, una cultura sana de valores para el éxito ampliamente compartidos por todos.

Conviene recapacitar, ya que el liderazgo es un asunto no sólo de poder, es también un asunto de autoridad. Quien no tiene autoridad reconocida por un equipo de trabajo podrá imponerse a base del miedo o de la necesidad de un empleo, pero no logrará resultados permanentes, y en cuanto voltee la espalda, se puede llevar desagradables sorpresas.

El líder ético debe tener una clara visión de futuro preservada por su optimismo, que integre a los miembros de su equipo, les inspire y les motive a luchar por unas metas fijadas que deberán ser alcanzadas empleando medios éticos. Dichos objetivos deberán ser concretos y específicos e implicarán a todas las partes de la organización, que buscarán, además de la prosperidad económica de la empresa, la consecución del bien común. De este modo, el líder deberá involucrarse elevando sus intereses por encima de su propia individualidad, en beneficio de la organización en su conjunto. 
El líder ético deberá coordinar a su grupo, basando sus relaciones en la confianza. Es imprescindible que delegue en sus subordinados determinadas tareas y deposite su fe en ellos, pues este comportamiento incentivará el desarrollo personal y profesional de los empleados al sentirse dueños de su propio trabajo. Este empowerment hará que los subordinados se encuentren a gusto en la empresa y trabajen con entusiasmo, lo cual es esencial pues "nadie puede ser líder en soledad. Se necesita liderar gente y esa gente tiene que sentir esa sensibilidad humana porque se dirigen a seres humanos" (López \& Díaz, 2006, p. 56).

La honradez, estrechamente relacionada con la integridad, antepone los principios morales a los beneficios personales de tipo económico derivados de actuaciones no éticas (Calzadilla, 2009).

El líder debe ser fiel con sus ideas y creencias y no cambiarlas en cuanto aparezcan los primeros obstáculos. La fortaleza está muy vinculada a la paciencia y a la perseverancia y es esencial en el liderazgo ético porque manifiesta la capacidad de los líderes de gobernarse a sí mismos: "Quien no se gobierna a sí mismo difícilmente lo hará con los demás" (Moreno, 2009, p. 134).

Un líder justo será un líder virtuoso. Si los subordinados observan que el líder da a cada uno lo que le corresponde sin dejarse llevar por favoritismos ganará en credibilidad. Por tanto, es posible afirmar que obrar con rectitud da reciedumbre al líder y lo hace confiable ante los demás (Calzadilla, 2009).
Pérez (1998) expresa:

Cuando un hombre de empresa no es capaz de mover a su gente más que a través de motivos económicos, es tan mal profesional como el médico que es incapaz de otra cosa que no sea atacar los síntomas que el enfermo dice que tiene. Cuando es capaz de mover a las personas a través de los trabajos que les ofrece y del aprendizaje profesional que le proporciona, ya está en otro nivel profesional; ya no es tan sólo un estratega sino un ejecutivo. Cuando es capaz de llegar a los subordinados a descubrir el valor y el sentido de lo que están haciendo, entonces, y sólo entonces, es un líder. (p. 74)

Hay mucha gente que logra ir de triunfo en triunfo hasta la derrota final, porque no aprendió lo más importante: su éxito no es unipersonal, tiene que ver con la capacidad de trabajar en equipo y reconocer que hay aspectos que otros hacen mejor.

\section{Conclusiones}

Actualmente las organizaciones están sometidas a constantes cambios y trances, donde el poder de la subjetividad y el relativismo de los valores han hecho perder el rumbo a las personas y a las corporaciones. Esto hace necesaria una vuelta al liderazgo ético, orientado hacia los fines y medios para alcanzar el bien común.

La literatura especializada examina diferentes conceptos, teorías, tipologias, prácticas y modelos de liderazgo, basados en la personalidad, la conducta, la contingencia, la transformación, el carisma y el humanismo. 
Aquí se trató de dos esquemas conductuales de liderazgo, el ético humanista y el amoral-que no inmoral- eficientista.

El liderazgo ético no es algo optativo en el mundo de hoy. Surge como una necesidad, en la cual, la confianza y no el poder coercitivo, construyen la autoridad de un líder. En las organizaciones se requiere que los líderes se conviertan en ejemplo vivo de respeto a la dignidad de las personas.

Hoy en día, hablar de valores en el mundo de las empresas suena para muchos como algo desentonado. Sólo algunas empresas hacen un esfuerzo real por introducirlos en su realidad empresarial.

Si se trastoca el concepto de valores por el de virtudes, sí que se ocasiona un embrollo. Pretender implantar valores en las personas que conforman las organizaciones resulta complicado, pretender implantar virtudes, es algo de verdad enmarañado.

El líder ético es el que reconoce a la persona en los demás en el ejercicio de su liderazgo y respeta la dignidad de las mismas.

El liderazgo humanista parte de la creencia de que los líderes son personas absolutamente normales, por ello considera que el liderazgo es un conjunto de prácticas observables que se pueden aprender, y que se sustenta en principios éticos, valores y competencias de éxito, que determinan la eficacia gerencial en la gestión de la organización.

\section{Referencias}

Álvarez, C.; Pérez, P.: Rodriguez, L. \& Rodríguez, T. (2002). "Paradigmas del Liderazgo”. Madrid: McGraw-Hill.

Barnard, C. (1968). "The Functions of the Executive”. Massachussets: Harvard University Press.

Burdeau, G. (1981). "Derecho constitucional e instituciones políticas". Madrid: Editora Nacional.

Bennis, W. \& Nanus, B. (2001). "Líderes. Estrategias para un liderazgo eficaz". Barcelona: Paidós Plural.

Calzadilla, R. (2009). Liderazgo ético en las universidades fundamentado en las virtudes humanas. "Universidad Católica Santa Rosa”. (Documento en formato html). Recuperado el o3 de septiembre del 2014 de: http://blog. ucsar.com

Del Aguila, R. (1999). "Modelos y estrategias del poder en Maquiavelo". México: Fondo de Cultura Económica.

Duguit, L. (1926). "Manual de Derecho Constitucional”. Madrid: Librería Española.

Etkin, J. (2005). "El potencial ético de las organizaciones. Las formas de integrar la eficacia con los valores sociales". Argentina: BID.

Fukuyama, F. (1995). "Trust: the social virtues and the creation of prosperity". Nueva York.: The Free Press. 
Simon, H. A.; Smithburg, D. W. \& Thompson, V. A. (1956). "Administración Pública”. San Juan: Universidad de Puerto Rico.

Jossey-Bass, P. (1998). “El círculo de la innovación”. Madrid, España: Atlántida.

Kousez, J. \& Posner, B. (2005). “El desafío del liderazgo. Cómo obtener permanentemente logros extraordinarios". Buenos Aires: Granica.

López, J. (2009). El liderazgo según Maquiavelo Word Press. (Documento en formato html). Recuperado el o5 de Septiembre del 2014 de: http://jordilopezcamps.wordpress.com/2009/o7/20/ el-liderazgo-segun-maquiavelo/

López, Z. \& Díaz, K. (2006). El liderazgo ético como una alternativa necesaria en la cultura organizacional cubana. "Red de Bibliotecas Virtuales de Ciencias Sociales". (Documento en formato html). Recuperado el 2 de septiembre del 2014 de: http://bibliotecavirtual. clacso.org.ar

Lussier, R. \& Achua, C. (2003). "Liderazgo. Teoría y aplicación. Desarrollo de Habilidades". México: Thomson Learning.

Maquiavelo, N. (1983). "El príncipe”. Barcelona: Teorema S. A.

Marrou, H. I. (2000). "Historia de la educación en la antigüedad”. México: Fondo de Cultura Económica.
McFarland, L.; Senn, L. \& Childress, J. (1997). "Liderazgo en acción. Liderazgo para el siglo XXI". Colombia: McGraw-Hill.

Mendoza, E. \& Mendoza, M. (20o8). El liderazgo ético en organizaciones postmodernas. "Revista de Artes y Humanidades", 9(22), 59-78.

Moreno, C. M. (2009). El liderazgo ético, un reto empresarial. (Documento en formato html). Recuperado el 03 de septiembre del 2014 de: http://www. rrhhmagazine.com

Murati, F. A. \& Pozo, J. M. (2013). Apuntes críticos sobre teorías y tipologías del liderazgo organizacional. "Contribuciones a la Economía”. (Documento en formato html) Recuperado el o5 de julio de 2014 de: http://www.eumed. net/ce/2013/liderazgo-organizacional. html

Oppenheirmer, A. (1998). Latinoamericanos: Un alto precio por su desconfianza. "Periódico Reforma", 15 de septimbre, p. 19-A.

Passerin D’entréves, A. (1970). "La Noción del Estado". Madrid: Centro de Estudios Universitarios.

Pérez, J. A. (1998). "Liderazgo y ética en la dirección de empresas. La nueva empresa del siglo XXI". Bilbao: Deusto.

Río, E. R. (1975). "El acto de gobierno". México: Porrúa. 
Ruíz, C. (2013). Ya lo decía Darwin: la empresa que sobrevive no es la más fuerte. "Revista Istmo. Publicación cultural de la Universidad Panamericana y el Instituto Panamericano de Alta Dirección". (Documento en formato html) Recuperado el o5 de septiembre del 2014 de: http://istmo. $\mathrm{mx} / 2013 / 09 /$ ya-lo-decia-darwin-la- empresa-que-sobrevive-no-es-la-masfuerte/

Soto, E. \& Cárdenas, J. (2007). "Ética en las organizaciones”. México: McGraw-Hill.

White, L. D. (1964). "Introducción al estudio de la administración pública”. México, D. F.: Compañía General de Ediciones.

Recibido: 18-08-2015

Aceptado: 20-10-2015 